\title{
Anatomía de la raíz y endófitos radicales en Podocarpus PARLATOREI (PODOCARPACEAE)
}

\author{
MARÍA F. LEONE1 ${ }^{1}$ ANA C. LUQUE¹, MARIANO ALMIRÓN¹, PATRICIA L. ALBORNOZ1,2 y \\ MARTA E. ARIAS ${ }^{1,3}$
}

\begin{abstract}
Summary: Root anatomy and root endophytes in Podocarpus parlatorei (Podocarpaceae). Podocarpus parlatorei Pilg. known as "mountain pine" is a tree up to $20 \mathrm{~m}$ tall, grows in mountain forests between 1500 and $2000 \mathrm{~m}$ asl and is the native only representative of the Gymnosperma in the NOA. The aim of this study was to characterize the anatomy of the root system and root endophytes in $P$. parlatorei comparatively between individuals of Tucuman and Catamarca. We applied conventional histological techniques and staining. The results showed that individuals from both provinces had the same structural feature in the different stages of development, differing in the number of layers in the cortical tissue. We observed the presence of arbuscular mycorrhizal with morphology Arum and Paris, both in root and nodules. For this species is recorded for the first time the presence of cells with non-lignified secondary thickening in the cortical parenchyma of the primary roots and nodules, whose function would be mechanical and absorption. The presence of arbuscular mycorrhizal fungi and dark septate endophytes in $P$. parlatorei is also reported for the first time for Argentina, and the morphology of these root endophytes is described.
\end{abstract}

Key words: Podocarpaceae, Podocarpus parlatorei, anatomy, root, endophytes.

\begin{abstract}
Resumen: Podocarpus parlatorei Pilg. conocido como "pino del cerro" es un árbol de hasta $20 \mathrm{~m}$ de altura, crece en los bosques montanos entre los 1500 y 2000 msm y es el único representante arbóreo autóctono de Gimnosperma en el norte de Argentina. El objetivo de este trabajo fue caracterizar la anatomía de la raíz y los endófitos radicales en $P$. parlatorei, comparativamente entre individuos de Tucumán y Catamarca. Se aplicaron técnicas histológicas y tinción convencionales. Los resultados evidenciaron que los individuos provenientes de ambas provincias presentaron la misma característica estructural en los distintos estadios de desarrollo, difiriendo en la cantidad de estratos en el tejido cortical. Se observó la presencia de endomicorrizas arbusculares con los tipos morfológicos Arum y Paris, tanto en raíces como en nódulos. Para la especie en estudio se cita por primera vez la presencia de células con engrosamientos secundarios no lignificados en el parénquima cortical de las raíces primarias y de los nódulos, cuya función sería mecánica y de absorción. Además, se cita por primera vez para Argentina la presencia de hongos micorrícicos arbusculares y de septados oscuros y se describe la morfología de ambos endófitos radicales en $P$. parlatorei.
\end{abstract}

Palabras clave: Podocarpaceae, Podocarpus parlatorei, anatomía, raíz, endófitos.

\section{INTRODUCCIÓN}

La familia Podocarpaceae (Gymnospermae) está formada por 17 géneros y aproximadamente

1 Cátedra Anatomía Vegetal. Facultad de Ciencias Naturales e Instituto Miguel Lillo, Universidad Nacional de Tucumán, Miguel Lillo 205, (4000) Tucumán. arias@ csnat.unt.edu.ar.

${ }^{2}$ Instituto de Morfología Vegetal, Fundación Miguel Lillo, Miguel Lillo 251, (4000) Tucumán. albornoz@csnat.unt. edu.ar.

3 Facultad Ciencias Exactas y Naturales, Universidad Nacional de Catamarca.
170 especies distribuidas en las regiones tropicales y subtropicales de ambos hemisferios (Zamudio, 2002). Podocarpus L'Hér. ex Pers. es el género más grande de la familia, comprende 100 especies distribuidas principalmente en el hemisferio Sur. En el continente americano presenta su mayor diversidad en Sudamérica (Zamudio, 2002). En Argentina, el género esta representado por tres especies: P. nubigena Lindl. de los bosques andinos-patagónicos, $P$. lambertii Klotz. de la selva misionera y $P$. parlatorei Pilg. de la selva yungueña, este último conocido vulgarmente como "pino del cerro" (Biloni, 1990).

P. parlatorei es el único representante arbóreo 
autóctono de Gimnosperma en el norte de Argentina, habita en los bosques montanos desde Bolivia hasta el noroeste de Argentina. Crece en manchones de laderas y quebradas, entre los 1500 y 2000 msm (Biloni, 1990; González et al., 1998; Anton \& Zuloaga, 2013). Es un árbol de hasta 20 $\mathrm{m}$ de altura, $1.5 \mathrm{~m}$ de diámetro, muy ramificado, hojas simples, lineares, falcadas, acuminadas, con semilla drupácea (Digilio \& Legname 1966; Anton \& Zuloaga, 2013).

El sistema radical de los géneros Dacrydium, Microstrobos, Phyllocladus, Podocarpus, Prumnopitys y Saxegothaea (Podocarpaceae) presenta nódulos. La caracterización morfoanatómica de los nódulos muestra un patrón estructural similar, pero variable en el tamaño, siendo los principales centros de colonización de hongos micorrícicos (Hooker, 1854; Spratt, 1912; Baylis et al., 1963; Bergersen \& Costin, 1964; Becking, 1965; Khan, 1967; Furman, 1970; Khan \& Valder, 1972; Medan \& Tortosa, 1981; Godoy \& Mayr, 1989). Los nódulos de Podocarpus se han considerado como una respuesta a la infección por bacterias o por hongos no septados (Khan, 1967).

Silver et al. (1963), atribuyeron a las bacterias presentes en los nódulos como las responsables de la fijación del nitrógeno. Además de los nódulos, el sistema radical presenta asociaciones micorrícicas de diferentes tipos como ectomicorriza, ectoendomicorriza y endomicorriza (Harley \& Smith, 1983; Mikola, 1988).

En cuanto a los antecedentes anatómicos se ha citado para $P$. henkelii la presencia de células especiales que presentan engrosamientos secundarios en la pared sin estar lignificados, las cuales fueron observadas en el tejido protálico de la semilla adyacente al embrión. Células similares se encuentran en diversos grupos tales como Briófitos, Algas, Hongos, Helechos, Angiospermas y Gimnospermas, recibiendo nombres y funciones diferentes. En este último grupo se encuentran en variados órganos de Picea sitchensis, Pinus sylvestris, Pinus pinea, P. henkelii (Offler et al., 2003; Stern \& Carlsward, 2006; Leroux et al. 2011).

Antecedentes anatómicos en $P$. parlatorei son citados por González et al. (1998), quienes describieron la anatomía foliar. Mientras que Luque et al. (2010), caracterizaron estructuralmente al pseudofruto.

Antecedentes relacionados con las micorrizas arbusculares en Gimnospermas de Argentina fueron citados por varios autores (Fontenla et al., 1991; Barroetaveña \& Rajchenberg, 2003a, b; Diehl $\&$ Fontenla, 2010). Debido a que no se registra información referida a la anatomía radical de esta especie y siendo la única gimnosperma nativa del noroeste de Argentina, en este trabajo se plantea como objetivo caracterizar la anatomía de la raíz y los endófitos radicales en $P$. parlatorei, comparativamente entre individuos de Tucumán y Catamarca.

\section{Materiales y Métodos}

Se tomaron muestras del sistema radical de 5 individuos en estadio de plántula colectados en Villa Nougués a $1.350 \mathrm{msm}\left(26^{\circ} 51^{\prime} \mathrm{S}\right.$; $65^{\circ} 22^{\prime} 44^{\prime \prime} \mathrm{W}$, Dpto. Lules, Tucumán), y de material proveniente de la cuenca del río Las Juntas, entre los 1000 y $2500 \mathrm{msm}\left(28^{\circ} 07^{\prime} 55^{\prime \prime} \mathrm{S}\right.$; 6554'6,6”W, Sierra de Ambato, San Fernando del Valle de Catamarca). Se realizaron secciones transversales utilizando técnicas de corte a mano alzada del sistema radical completo (D'Ambrogio de Argüeso, 1986). Dichas secciones fueron teñidas con safranina, azul de cresilo brillante y azul astral-safranina, posteriormente montadas en agua glicerina (1:1).

Para la detección de micorrizas arbusculares y hongos septados oscuros las raíces fijadas en FAA fueron clarificadas con $\mathrm{KOH}$ al $10 \%$, acidificadas con $\mathrm{HCl} 0,1 \mathrm{~N}$ y teñidas con Azul de Tripán en glicerina (Phillips \& Hayman, 1970). Por cada individuo se observaron, en microscopio óptico, 15 fragmentos de $1 \mathrm{~cm}$ de raíces teñidas, las que fueron montadas en agua glicerina (1:1).

Las observaciones se efectuaron con microscopio óptico (Zeiss, Axiostar Plus), microscopio de luz polarizada (Enosa) y microscopio estereoscópico (Nikon). Las fotos fueron tomadas con cámara digital (Cannon A620, Power Shot 7,1 MP).

Se realizaron 30 mediciones, por individuo, del diámetro de raíz y estela, mientras que para traqueidas fueron 90 mediciones.

\section{Resultados}

Los resultados anatómicos del sistema radical de $P$. parlatorei evidenciaron que los individuos 
de Catamarca y Tucumán presentan la misma característica estructural; difiriendo en la cantidad de estratos del parénquima cortical, presentando de 4 a 8 capas de células los individuos de Tucumán y 4 estratos los de Catamarca. El análisis comparativo de los diferentes tejidos del sistema radical de los ejemplares colectados en Catamarca y Tucumán, se muestra en la Tabla 1.

\section{Anatomía de la estructura primaria de raíz}

En sección transversal, la estructura primaria presenta una epidermis uniestratificada, parénquima cortical de 4-8 estratos de células (Fig. 1A), endodermis uniestratificada con banda de Caspary radial, periciclo pluriestratificado y estela diarca (Fig. 1B). Las células del parénquima cortical presentan en sección transversal, engrosamientos de paredes secundarias no lignificadas en forma de Y (Fig. 1C).

\section{Anatomía de la estructura secundaria temprana de raiz}

En sección transversal se evidenciaron diferentes estadios de desarrollo, caracterizándose por presentar córtex primario adherido a la peridermis en formación (Figs. 1D, F; 2A). Las células parenquimáticas de la corteza secundaria (2-5 estratos), no presentan los engrosamientos de pared observados en el córtex primario. Diferentes estadios de desarrollo del xilema y floema secundarios fueron observados (Fig. 1E, F). Se detectaron granos de almidón con hilo excéntrico puntiforme en células de la corteza, y fibras mucilaginosas en el floema (Fig. 2A, B).

\section{Anatomía de la estructura secundaria de raíz}

En sección transversal se observa peridermis pluriestratificada formada por suber, felógeno y felodermis, una corteza parenquimática (3-5 estratos), y el xilema secundario con hasta 3 anillos de crecimiento, cada uno de ellos con leño tardío y leño temprano (Fig. 2C, D). En el floema se observa la presencia de fibras mucilaginosas (Fig. 2E), similares a las encontradas en el córtex de la raíz del estadio anterior. Las traqueidas presentan engrosamiento anular, helicoidal y puntuaciones areoladas en una hilera, se ilustran estas últimas (Fig. 2F). Se observaron granos de almidón similares al estadio anterior en la corteza y arenas cristalinas de oxalato de calcio en el parénquima de la corteza y floema.
Tabla 1. Variables anatómicas de raíces en

diferentes estadios de crecimiento de Podocarpus parlatorei.

\begin{tabular}{|c|c|c|}
\hline & $\begin{array}{l}\text { Individuos } \\
\text { Tucumán }\end{array}$ & $\begin{array}{l}\text { Individuos } \\
\text { Catamarca }\end{array}$ \\
\hline \multicolumn{3}{|l|}{ Estructura primaria } \\
\hline $\mathrm{N}^{0}$ estratos corteza & 4 a 8 & 4 \\
\hline Diámetro raíz & 362,5 a $475 \mu \mathrm{m}$ & 437,5 a $475 \mu \mathrm{m}$ \\
\hline Diámetro estela & 132 a $187,5 \mu \mathrm{m}$ & 155,1 a $165 \mu \mathrm{m}$ \\
\hline Diámetro traqueida & 6,6 a $16,5 \mu \mathrm{m}$ & 9,9 a $13,2 \mu \mathrm{m}$ \\
\hline \multicolumn{3}{|c|}{ Estructura secundaria temprana } \\
\hline$N^{\circ}$ estratos corteza & 2 a 5 & 4 a 5 \\
\hline Diámetro raíz & 500 a $1870 \mu \mathrm{m}$ & 562,5 a $695,4 \mu \mathrm{m}$ \\
\hline Diámetro estela & 198 a $1458,6 \mu \mathrm{m}$ & 115,5 a $330 \mu \mathrm{m}$ \\
\hline Diámetro traqueida & 9,9 a $19,8 \mu \mathrm{m}$ & 9,9 a $13,2 \mu \mathrm{m}$ \\
\hline \multicolumn{3}{|c|}{ Estructura secundaria } \\
\hline $\mathrm{N}^{\circ}$ estratos corteza & 3 a 5 & 3 a 5 \\
\hline \multirow[t]{2}{*}{ Diámetro raíz } & 887,5 a & 687,5 a $887,5 \mu \mathrm{m}$ \\
\hline & $1250,5 \mu$ & \\
\hline Diámetro estela & 412,5 a $875 \mu \mathrm{m}$ & 462,5 a $562,5 \mu \mathrm{m}$ \\
\hline Diámetro traqueida & 9,9 a $19,8 \mu \mathrm{m}$ & 9,9 a $19,8 \mu \mathrm{m}$ \\
\hline
\end{tabular}

Las mediciones referidas a los diámetros de raíz, estela y elementos traqueales se muestran en la Tabla 1.

\section{Descripción de nódulos radicales}

Los nódulos radicales son, generalmente, de forma esférica, se originan del periciclo y por proliferación de células de la corteza de raíz primaria (Fig. 3A). Las células parenquimáticas del nódulo presentan los mismos engrosamientos secundarios no lignificados, en forma de $\mathrm{Y}$, que los observados en las células del córtex de la raíz primaria (Fig. 3A). En el tejido cortical de los nódulos se observó la presencia de bacterias y estructuras de hongos Glomeromycota.

\section{Micorrizas arbusculares y hongos septados oscuros}

El sistema radical y los nódulos presentan interacciones con hongos Glomeromycota; donde la hifa cenocítica presenta dos morfologías diferentes:

1) Morfología Tipo Arum, con hifas intercelulares que se ubican paralelas al eje longitudinal de la raíz, forman estructura en $\mathrm{H}$, con ramas laterales cortas que originan arbúsculos intracelulares y vesículas terminales. El diámetro promedio de las hifas es de 2,6 $\mu \mathrm{m}$ (Fig. 3B, C, D).

2) Morfología Tipo Paris, con hifas intracelulares que forman circunvoluciones en el parénquima cortical de la raíz. Este tipo fue el más frecuentemente encontrado y el diámetro promedio de las hifas fue de 2,92 $\mu \mathrm{m}$ (Fig. 3D). 
Bol. Soc. Argent. Bot. 49 (2) 2014
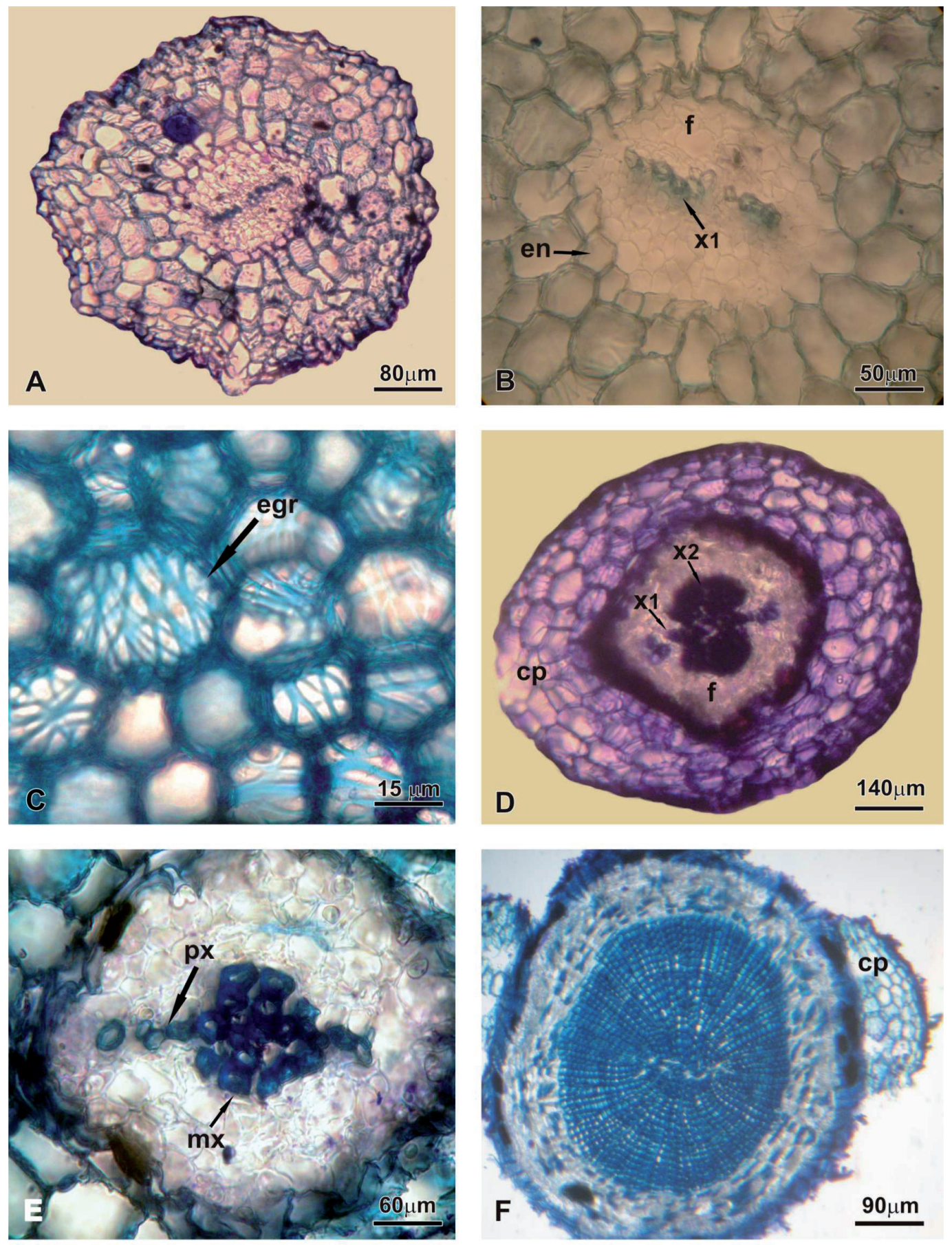

Fig. 1. Podocarpus parlatorei. Anatomía radical en sección transversal. A-C: Raíz primaria. A: Aspecto general. B: Detalle del cilindro vascular. C: Células corticales con engrosamientos de pared secundaria sin lignificar. D-F: Distintos estadios de raíz con crecimiento secundario temprano. D: Transición de estadio primario a secundario temprano. E: Detalle del cilindro vascular. F: raíz secundaria temprana con la corteza primaria aún adherida a la peridermis. Referencias: Abreviaturas: $\mathrm{cp}$, corteza primaria; egr, engrosamiento; en, endodermis; f, floema; mx, metaxilema; px, protoxilema; $\mathrm{x}$, xilema. 

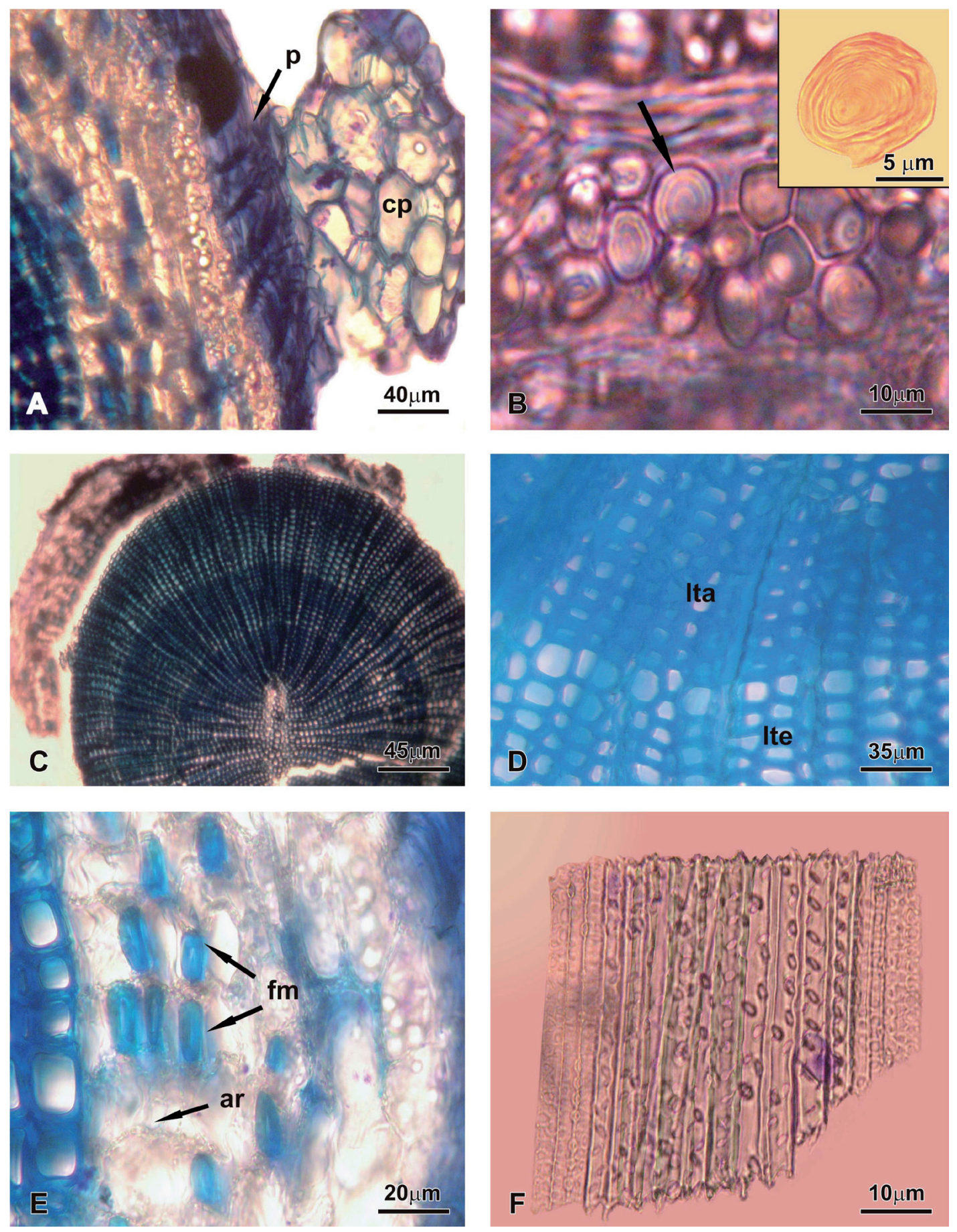

Fig. 2. P. parlatorei. Anatomía radical. A-E: Sección transversal. A: Detalle de peridermis en formación, con corteza primaria adherida. B: Granos de almidón, en figura incluida detalle de grano simple con hilo excéntrico. C: Aspecto general de de raíz secundaria. D: Detalle del xilema. E: Detalle de fibras mucilaginosa y arenillas en floema. F: Traqueidas con punteadura areolada en sección longitudinal. Abreviaturas: ar, arenilla; $\mathrm{cp}$, corteza primaria; fm, fibras mucilaginosas; Ita, leño tardío; Ite, leño temprano; $p$, peridermis. 
Bol. Soc. Argent. Bot. 49 (2) 2014
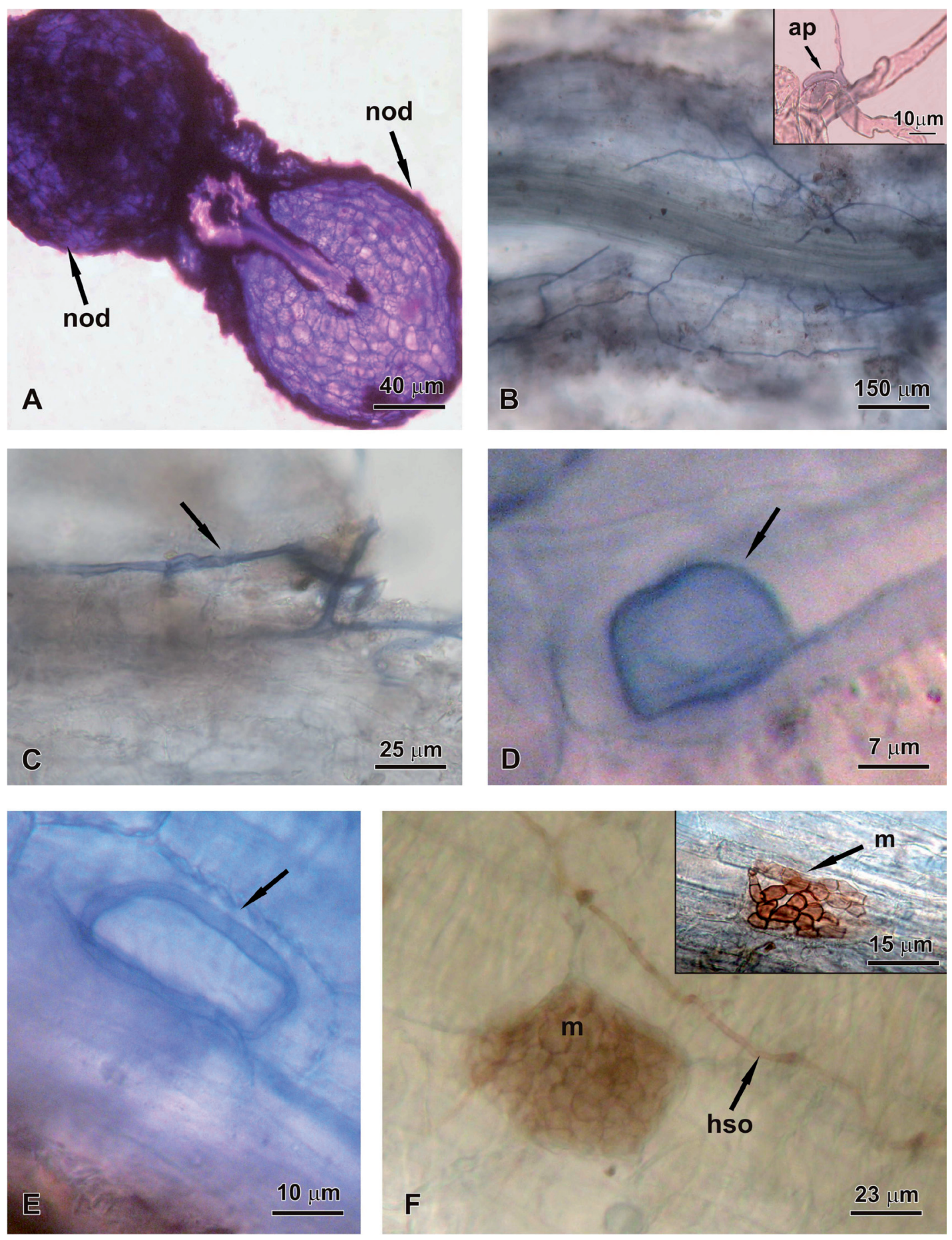

Fig. 3. P. parlatorei. Anatomía radical, morfología de las endomicorrizas arbusculares y anamorfos dematiáceos. A: Sección transversal de raíz con dos nódulos laterales (nod). B-E: Micorrizas arbusculares. B-D: Hifas Tipo Arum. B: Aspecto de raíz con hifas Glomeromycota, en imagen incluída detalle del aprosorio (ap). C: Detalle de hifas cenocíticas. D: Vesícula. E: Hifa Tipo Paris. F: Hongos septados oscuros (hso) y microesclerocio $(\mathrm{m})$, en imagen incluída detalle de microesclerocio $(\mathrm{m})$. 
Los hongos septados oscuros (anamorfos dematiáceos) se caracterizan por las hifas estrechas septadas de color marrón, recorren la raíz en forma paralela al eje longitudinal de la misma y en determinados lugares penetran en las células corticales ocupándola con microesclerocios (Fig. 3E). Las hifas de estos hongos presentan un diámetro promedio de $1,3 \mu \mathrm{m}$.

\section{Discusión y Conclusiones}

La estructura anatómica de la raíz de los individuos de Podocarpus parlatorei analizados, presenta características semejantes en los distintos estadios de desarrollo. La presencia de micorrizas arbusculares, en Argentina, fue mencionada por Diehl \& Fontenla (2010), para Araucaria; Barroetaveña \& Rajchenberg (2003a, b) en Pseudotsuga y Pinus. El primer autor caracteriza la morfología de tipo Paris en $A$. araucana. En P. parlatorei nosotros observamos los tipos morfológicos Arum y Paris. La ocurrencia de ambos tipos morfológicos, Arum y Paris, indica la presencia de más de un hongo de este grupo asociado al sistema radical. En Angiospermas también fueron citados ambos tipos morfológicos en distintas especies (Dickson, 2004).

En cuanto a los nódulos presentes en las raíces de esta especie son de forma esférica, similar a los descriptos en $P$. nubigena y $P$. salignus (Godoy \& Mayr, 1989). Con respecto al origen, algunos autores consideran que se forman a partir del periciclo, a la altura de un polo protoxilemático, causando la ruptura de la endodermis y el aplastamiento de la corteza suprayacente. Las divisiones celulares en el periciclo darían lugar a un nuevo nódulo, por lo que los nódulos de tipo Podocarpus podrían considerarse una modificación de las raíces laterales (Becking, 1965; Medan \& Tortosa, 1981). Según Fahn (1985), las bacterias ingresan en el córtex a través de los pelos absorbentes, se multiplican y forman colonias que penetran profundamente en este tejido de la raíz, induciendo la proliferación de sus células. $\mathrm{Al}$ principio, el número de células en el nódulo se incrementa por división a lo largo de toda la masa de células y, más tarde, por la actividad de una región meristemática localizada apicalmente que no es invadida por bacterias. En este trabajo interpretamos que los nódulos de las raíces de $P$. parlatorei presentan un doble origen, a partir del periciclo y de células de la corteza de la estructura primaria, esto último se evidencia por la presencia de engrosamientos secundarios no lignificados en las células corticales del nódulo.

En relación a las células con engrosamientos secundarios no lignificados, éstos fueron registrados en diversos grupos de plantas encontrándose en raíces, nódulos y hojas entre otros; también se los detectaron en algas y en hifas de hongos (Offler et al., 2003; Stern \& Carlsward, 2006; Leroux et al.2011). Estas células fueron descriptas en el tejido protálico adyacente al embrión para $P$. henkelii (Offler et al., 2003). Existe controversia en cuanto a la función de estas células. Algunos autores las consideran un refuerzo mecánico, estabilizando la corteza, permitiendo una absorción más eficiente de agua y nutrientes y previniendo la desecación del sistema vascular (Leroux et al., 2011). Por otro lado, Gunning et al. (1968) y Offler et al. (2003) sugieren que estas células tendrían la función de transporte de solutos. Según Offler et al. (2003), la diferenciación de este tipo de células estaría coordinada con el desarrollo de órganos y se produciría en lugares específicos, o sería inducida como respuesta a tensiones externas, tales como la deficiencia de nutrientes, invasión por organismos simbióticos o parásitos o ataque de nemátodos. Bajo estos conceptos, en el caso de P. parlatorei, se puede interpretar que la presencia de estas células en tejidos corticales de la raíz y de los nódulos tendría una función principalmente mecánica, ya que dichas estructuras presentan crecimiento primario. Probablemente las células con engrosamientos presenten una función secundaria aumentando la capacidad de absorción de nutrientes, favorecida por la interacción con hongos endomicorrícicos arbusculares.

Se citan por primera vez, en $P$. parlatorei, la presencia de células con engrosamientos secundarios no lignificados en el parénquima cortical de las raíces primarias y de los nódulos. Además, se cita por primera vez para Argentina la presencia de hongos micorrícicos arbusculares y de septados oscuros y se describe la morfología de ambos endófitos radicales en P. parlatorei.

\section{Agradecimientos}

Al Sr. Alberto Gutiérrez de la sección Iconografía de la Fundación Miguel Lillo por su colaboración en la calidad de las microfotografías. 


\section{Biblografía}

ANTON, A. M. \& F. O. ZULOAGA. 2013. Flora Argentina. Disponible en: http://www.floraargentina.edu.ar/ [Acceso: 31 julio 2013].

BARROETAVEÑA, C. \& M. RAJCHENBERG. 2003a. Las micorrizas y la producción de plántulas de Pseudotsuga menziesii (Mirb.) Franco en la Patagonia, Argentina. Bosque 24: 3-15.

BARROETAVEÑA, C. \& M. RAJCHENBERG. 2003b. Las micorrizas y la producción de plántulas de Pinus ponderosa Dougl. ex Laws. en la Patagonia, Argentina. Bosque 24: 17-33.

BAYLIS, G. T. S., R. F. R. Mc NABB \& T. M. MORRISON. 1963. The mycorrhizal nodules of podocarps. T. Brit. Mycol. Soc. 46: 378-384.

BECKING, J. H. 1965. Nitrogen fixation and mycorrhiza in podocarpus root nodules. Plant Soil 23: 213-226.

BERGERSEN, F. J. \& A. B. COSTIN. 1964. Root nodules on Podocarpus lawrencei and their ecological significance. Aust. J. Biol. Sci. 17: 44-48.

BILONI, J. S. 1990. Árboles Autóctonos Argentinos de las selvas, bosques y montes de la Argentina. Editora Tipográfica Argentina, Buenos Aires.

D' AMBROGIO DE ARGÜESO, A. 1986. Manual de técnicas en histología vegetal. Editora Hemisferio Sur, Buenos Aires.

DICKSON, S. 2004. The Arum-Paris continuum of mycorrhizal symbioses. New Phytologist 163: 187-200.

DIEHL, P. \& S. B. FONTENLA. 2010. Arbuscular mycorrhizal infection in two morphological root types of Araucaria araucana (Molina) K. Koch. Revista Argentina de Microbiología 42: 133-137.

DIGILIO, A. P. L. \& P. R. LEGNAME. 1966. Los Árboles Indígenas de la Provincia de Tucumán. Opera Lilloana 15: 1.

FAHN, A. 1985. Anatomía Vegetal. Ed. Pirámide, S.A. Madrid.

FONTENLA, S.; M., HAVRYLENKO \& P., ROSSO 1991. Micorrizas vesículo-arbusculares en Austrocedrus chilensis. Suelo y planta 1: 251-5.

FURMAN, T. E. 1970. The nodular mycorrhizae of Podocarpus rospigliosii. Am. J. Bot. 57: 910-915.

GODOY, R. \& R. MAYR. 1989. Caracterización morfológica de micorrizas vesículo-arbusculares en coníferas endémicas del sur de Chile. Bosque. 10: 89-98.

GONZÁlEZ, J., G. PONESSA, M. T. DE PLAZA, M. PARRADO, M. ARIAS \& L. B. PARRA. 1998. Variaciones en la morfología foliar de Podocarpus parlatorei Pilger (Podocarpaceae), según la posición espacial de la hoja en la copa. Lilloa 39: 129-135.

GUNNING, B. E. S., J. S. PATE \& L. G. BRIARTY. 1968. Specialized "transfer cells" in minor veins of leaves and their possible significance in phloem translocation. $J$. Cell. Biol. 37: 7-12.
HARLEY, J. \& S. SMITH. 1983. Mycorrhizal Symbiosis. Academic Press, New York.

HOOKER, J. D. 1854. On some remarkable spherical exostoses developed on the roots of various species of Coniferae. Proc. Linn. Soc. Lon. 2: 335-336.

KHAN, A. G. 1967. Podocarpus root nodules in sterile culture. Nature 215: 1170.

KHAN, A. G. \& P. G. VALDER. 1972. The occurrence of root nodules in the Ginkgoales, Taxales, and coniferales. P. Linn. Soc. N.S.W. 97: 35-41.

LEROUX, O., A. BAGNIEWSKA-ZADWORNA, S. K. RAMBE, J. P. KNOX, S. E. MARCUS, E. BELLEFROID, D. STUBBE, B. CHABBERT, A. HABRANT, M. CLAEYS \& R. L. L. VIANE. 2011. Non-lignified helical cell wall thickenings in root cortical cells of Aspleniaceae (Polypodiales): histology and taxonomical significance. Ann. Bot. London 7: 195-207.

LUQUE, A. C., J. BARROS, O. VARELA \& M. ARIAS. 2010. Estudio Anatómico del Pseudofruto de Podocarpus Parlatorei Pilg. Ciencia 5: 51-58.

MEDAN, D. \& R. D. TORTOSA. 1981. Anatomy of the root and stem nodules of Dacrydium fonckii (Phil.) Florin (Podocarpaceae). Bot. J. Linn. Soc. 83: 85-91.

MIKOLA, P. 1988. Ectendomycorrhiza of conifers. Silva Fenn. 22: 19-27.

OFFLER, C. E., D. W. MCCURDY, J. W. PATRICK \& M. J. TALBOT. 2003. Transfer Cells: Cells Specialized for a Special Purpose. Supplemental Material. Annu. Rev. Plant Biol. 54: 431-454.

PHILLIPS, J. M. \& D. S. HAYMAN. 1970. Improved procedures for clearing roots and staining parasitic and vesicular-arbuscular mycorrhizal fungi for rapid assessment of infection. Transaction of the British Mycological Society 55: 158-161.

SPRATT, E. R. 1912. The formation and physiological significance of root nodules in the Podocarpineae. Ann. Bot. London 26: 801-813.

SILVER, W. S., Y. M CENTIFANTO \& D. J. D. NICHOLAS. 1969. Nitrogen fixation by the leaf nodule endophyte of Psychotria bacteriophila. Nature 199: 396-397.

STERN, W. L. \& B. S. CARLSWARD. 2006. Comparative vegetative anatomy and systematics of the Oncidiinae (Maxillarieae, Orchidaceae). Bot. J. Linn. Soc. 152: 91-107.

ZAMUDIO, S. 2002. Flora del Bajío y de regiones adyacentes. Podocarpaceae Instituto de Ecología, A.C. Centro Regional del Bajío Pátzcuaro, Michoacán. Fascículo 105: 1-2. Disponible en: http://www1.inecol. edu.

$\mathrm{mx} /$ publicaciones/resumeness/FLOBA/Flora $\% 20$ 105-Podocarpaceae [Acceso: 20 Julio 2013]

Recibido el 5 de agosto de 2013, aceptado el 29 de noviembre de 2013 . 